\title{
UNOS COBRES FLAMENCOS DEL SIGLO XVII EN TALCA (CHILE)
}

\author{
SOME FLEMISH OIL ON COPPER PAINTINGS FROM \\ THE 17TH CENTURY IN TALCA (CHILE)
}

\section{ALBERT FERRER ORTS*, ESTEFANÍA FERRER DEL RÍO $^{* *}$, GONZALO OLMEDO ESPINOZA***}

\section{RESUMEN}

En este estudio presentamos cuatro pinturas sobre cobre de ascendencia flamenca, una de ellas firmada por Willem van Herp (1614-1677), a quien también atribuimos las restantes. Obras tal vez de la segunda mitad del siglo XVII e inspiradas en Rubens y Teniers el Viejo que, en su mayoría, pertenecieron a Eusebio Lillo y hoy se custodian en el Museo O’Higginiano y de Bellas Artes de Talca (Chile).

Palabras clave: Pinturas de cobre, Flandes, Willem van Herp, siglo XVII, Talca (Chile).

\section{ABSTRACT}

In this study we present four oil on copper paintings of Flemish descent, one by Willem van Herp (1614-1677), whom we also attribute the remaining ones. His works may date back to the second half of the 17th century and are inspired by Rubens and Teniers the Elder: Most of them belonged to Eusebio Lillo and nowadays they are kept at the O'Higgins' and Fine Arts Museum in Talca (Chile).

Keywords: Paintings, oil on copper, Flanders, Willem van Herp, 17th Century, Talca, Chile.

Recibido: 20.03.14. Aceptado: 18.09 .14 .

* Dpt. d'Història de l'Art, Universitat de València. Meliana, España. Correo electrónico: Albert.Ferrer-Orts@uv.es

** Universitat de València. Meliana, España. Correo electrónico: ferrer.delrio@gmail.com

${ }^{* * *}$ Museo O’Higginiano y de Bellas Artes de Talca. Talca, Chile. Correo electrónico: gonzalo. olmedo@museosdibam.cl 
$\mathrm{D}$ ESDE HACE TIEMPO se viene sopesando el impacto de la comercialización de pinturas de procedencia norte europea, flamenca para más señas, en Latinoamérica a través de los virreinatos de la Nueva España y del Perú (Díaz, 1981, pp. 61-76 y 1998, pp. 17-25; Bargellini, 1999, pp. 79-98), un hecho que entra dentro de lo razonable por cuanto desde Amberes, centro de gran trasiego artístico entre los siglos XVI y XVII tan ligado a la monarquía hispánica, se exportaban numerosas pinturas, grabados y láminas a los principales puertos castellanos que, como Santander, Bilbao, Cádiz, Sevilla o Málaga, abastecían el consumo interno como también el de sus colonias allende el Atlántico (Balis, 1985, p. 294; Fernández y Blanco, 1996; Rodríguez, 2005, p. 101; Komanecky, 1999; Sánchez, 2011, pp. 486-488).

En verdad, la llegada a tierras americanas de numerosas obras artísticas con esta procedencia y, con ellas, de artífices venidos del Viejo Mundo (Mesa-Gisbert, 2005) se enmarca ineludiblemente en la necesidad de los evangelizadores, encarnados principalmente por franciscanos, dominicos, agustinos, hospitalarios y jesuitas, así como por los nuevos cabildos, de dotar a sus fundaciones, misiones, catedrales, parroquias y santuarios del ornato digno de la Iglesia católica antes y después de la Contrarreforma para así contribuir a la difusión ortodoxa de su doctrina. Tal como sucediera en la Española en tiempos de Cristóbal Colón, en la Nueva España desde Hernán Cortés, en el Perú a partir de Francisco Pizarro y, posteriormente, de Nueva Granada o del Río de la Plata (Gruzinski, 1994). Aunque, al mismo tiempo, también fueron satisfaciendo los gustos estéticos de otro tipo de clientela laica acomodada de origen criollo.

En este contexto, se ha insistido en la importancia que particularmente desempeñaron los grabados, pues no en vano la ciudad del Escalda poseía, además de activos obradores artísticos, una producción editorial sobresaliente a través del floreciente negocio impresor. Un hecho que, desde la segunda mitad del siglo XVI, marcó no sólo el devenir de la pintura española, sin ir más lejos, sino que también incidió sobremanera en la incipiente plástica americana. La facilidad en realizar miles de reproducciones de pinturas ya consagradas de maestros como Rubens, Van Dyck, Jordaens, los Teniers..., su economía y fácil transporte fueron, sin duda, razones de peso para su ágil y rápida distribución.

Entrados en el siglo XVII, otro tipo de soporte, la plancha de cobre, fue tomando cuerpo en este incesante y lucrativo trasiego artístico euro- 
peo hasta competir con otros formatos al uso hasta ese momento, aunque quienes primero experimentaron sobre este material fueron los italianos (Bargellini, 1999, pp. 80-81). Los activos obradores flamencos, estratégicamente impulsados por agentes comerciales o marchantes diseminados por las principales plazas, habituados a un tipo de producción digamos industrial, verán incrementados exponencialmente sus encargos y su difusión en países como España, desde donde se catapultaron hacia sus colonias ultramarinas (Díaz, 1978a, pp. 9-19 y 1995; Payo, 1998/2, pp. 289-291; Bargellini, 1999, pp. 79-98; Rodríguez, 2005, pp. 100-102; Komanecky, 1999; Sánchez, 2011, pp. 486-488). Influjo éste que ha sido estudiado en los dos primeros virreinatos pero que, aunque se suponga, todavía no ha dado los mismos frutos en tierras australes, caso de Argentina y Chile.

La labor de estudio que venimos realizando de un tiempo a esta parte en la colección de pinturas de procedencia europea que conserva el $\mathrm{Mu}-$ seo O'Higginiano y de Bellas Artes de Talca-MOBAT- (Ferrer, en prensa), uno de los espacios museísticos más interesantes de Chile y curiosamente menos conocidos, especialmente desde su clausura a raíz de los terribles efectos del seísmo del 27 de febrero de 2010, nos ha deparado algunas sorpresas, como la localización de unos cobres de ascendencia flamenca que a continuación relatamos.

El MOBAT se halla ubicado en una casona de estilo colonial que es, a su vez, Monumento Histórico-Nacional. Un lugar en el que hasta hace relativamente poco se creía que Bernardo O’Higgins había firmado el Acta de Independencia del país andino y que este año celebra su medio siglo de vida, si bien no siempre estuvo situado en esta demarcación (González, 2014).

Como institución cultural perteneciente a la Dirección de Bibliotecas, Archivos y Bibliotecas (DIBAM) de Chile, entre sus muros se halla una buena colección de objetos artísticos, además de los propiamente históricos, hasta el punto de custodiar un número considerable de pinturas y dibujos (344), esculturas (157) y fotografías hoy almacenadas y no expuestas por los motivos que antes referenciamos. Su repertorio de pintura europea -sin considerar la española- se compone de obras de conocidos artífices, entre los que destacan los alemanes Rugendas y Kirchbach, los franceses Monvoisin o Allongé y los italianos Migliaro o Brancaccio, como también belgas y holandeses. Entre los primeros, Van Herp o Eliaerts y entre sus vecinos del norte Cuyp, Schelfhout, Van Wijk y Mauve (Ferrer, en prensa).

En particular, la nutrida nómina de pintores procedentes de los Países 
Bajos es la que más llama la atención con sus creaciones de reducido formato, predominantemente de naturalezas muertas, paisajes rurales y marinas, sin olvidar las de cariz mitológico y religioso. Entre estas últimas hemos contabilizado cuatro que son las que ahora traemos a colación dado que, además, están ejecutadas sobre planchas de cobre, tres sin firmar y una autógrafa de Willem van Herp (Amberes, 1614-1677).

Precisando más, las dos más reducidas podrían hacer pareja por sus tamaños y temáticas moralizantes y piadosas -no así las otras dos obras, ligeramente diferentes-, algo a lo que no eran ajenos los talleres flamencos que, a menudo, realizaban series con diversas narraciones. Las de menor tamaño están dedicadas tanto a San Antonio Abad como a María Magdalena, quienes aparecen de cuerpo entero y en formato vertical; mientras que las de mayor aparato desarrollan sus escenas horizontalmente y versan a nuestro parecer sobre la "Parábola del banquete de bodas" y las "Obras de la Misericordia", tanto las corporales como -en menor medida- las espirituales. Pasajes de las Sagradas Escrituras que se recogen convenientemente tanto en $\mathrm{Mt}$ 22: 1-14, Lc 14: 15-24 y Tm 64, como en Mt 6: 2-4, Mt 25: 31-46, Tb 4: 5-11 y Si 17:22, respectivamente, y en los que se inspiraron su autor o autores.

De todas estas obras sólo una aparece firmada como VAN HERP, sin embargo un examen exhaustivo de todas ellas conduce a pensar que fueron o bien él y sus colaboradores u otros artífices cercanos estilísticamente y estrictamente contemporáneos sus autores materiales, por su inspiración en modelos de Rubens y de Teniers el Viejo mayormente, su calidad, su formato complementario y su temática, ya que seguramente se ejecutarían en la segunda mitad del Seiscientos, cuando su frenética actividad se potenció sobremanera. Pintor al que le han dedicado numerosos trabajos estudiosos de la pintura flamenca en España como Valdivieso (1973), Díaz Padrón (1975, 1976, 1977, 1978ab, 1982, 1988 y 2003) y Sanzsalazar (2001, 2003 y 2013), entre otros colegas ya citados.

\section{"LAS TENTACIONES DE SAN ANTONIO ABAD"}

(Óleo sobre cobre, 24,7 x 18,7 cm; registro 7-27, inventario 1.27: "El ermitaño"; Legado de Eusebio Lillo, 1910).

El santo eremita por excelencia y de vida longeva aparece sentado en plena naturaleza como un anciano cubierto con su hábito, mientras con una mano sostiene un libro y con la izquierda un cayado. Está inmerso en la 


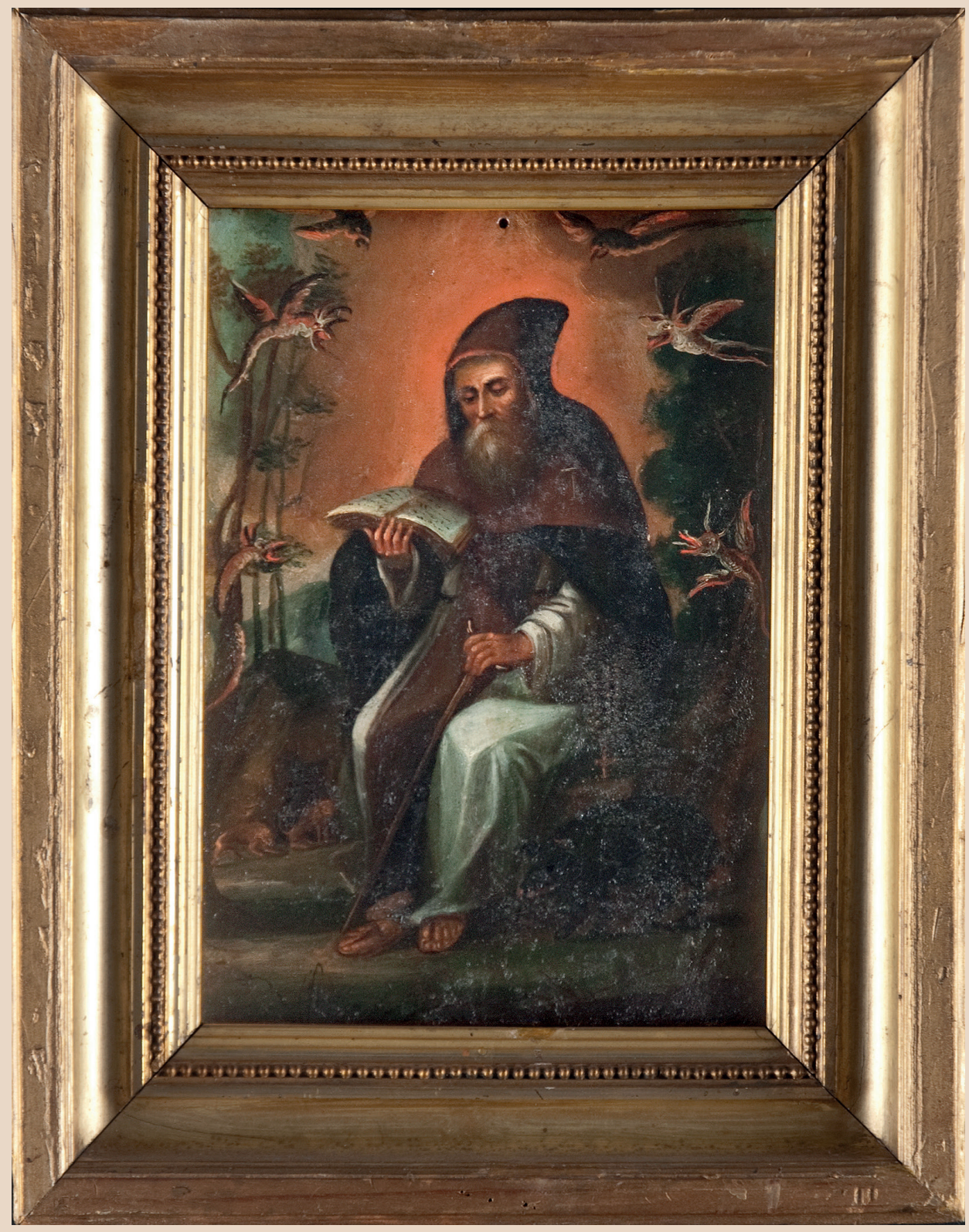

1. “Tentaciones de San Antonio Abad”, MOBAT. Foto Viviana Rivas, Centro Nacional de Conservación y Restauración, DIBAM. 
lectura a pesar de las tentaciones que, como animales extraños e híbridos, le sobrevuelan hasta rodearlo, según consta en un episodio relativo a su hagiografía en la Leyenda dorada de Santiago de la Vorágine. La calidad de su rostro es innegable, tal como su impoluto atuendo, los cuales destacan en una penumbra solo mitigada por la aureola que desprende. El tratamiento del paisaje, diferente al desierto en el que se describe la acción en el texto, es abocetado y secundario, no así la figura de San Antonio que sale sobredimensionada del contraste. La pintura presenta un orificio en su parte central superior, lo que indica que en algún momento estuvo colgada sin el marco que hoy le acompaña y que también se nos antoja original (de "rizo", conocido como flammenleisten), tal como sucede en la de María Magdalena.

\section{“MARÍA MAGDALENA PENITENTE”}

(Óleo sobre cobre, 0,22 x 0,17 m; registro 7-50, inventario 1.50: "Magdalena en el desierto"; Legado de Eusebio Lillo, 1910).

La Magdalena aparece como penitente con los tradicionales atributos que se le asocian mientras arrodillada se arrepiente por sus pecados retirada del mundo, como un eremita, a nuestro parecer en conexión con Santa María Egipcíaca. A diferencia de esta última, quien se muestra en edad de senectud en las representaciones, María Magdalena se nos presenta joven y hermosa ataviada de una túnica escarlata aferrada a un paño blanco, símbolo de pureza espiritual y arrepentimiento en este contexto, pero sobre todo signo indiscutible que la señala como testigo privilegiado de la pasión y muerte de Jesús como también de su ulterior resurrección.

Otros símbolos, que forman una naturaleza muerta, la acompañan en su retiro y penitencia, como una serie de libros, la calavera, un flagelo y una ampolla de vidrio de sutil elegancia con perfume. El paisaje se resume en una oquedad en penumbra en el cual destaca una potente llamarada celestial que unge a la protagonista y contribuye a destacar su larga y rubia cabellera como su cuerpo y torso semidesnudo.

En esta composición, las deudas con Rubens son más que evidentes, especialmente su intenso cromatismo y la calidad de su realización hasta en los más mínimos detalles. 


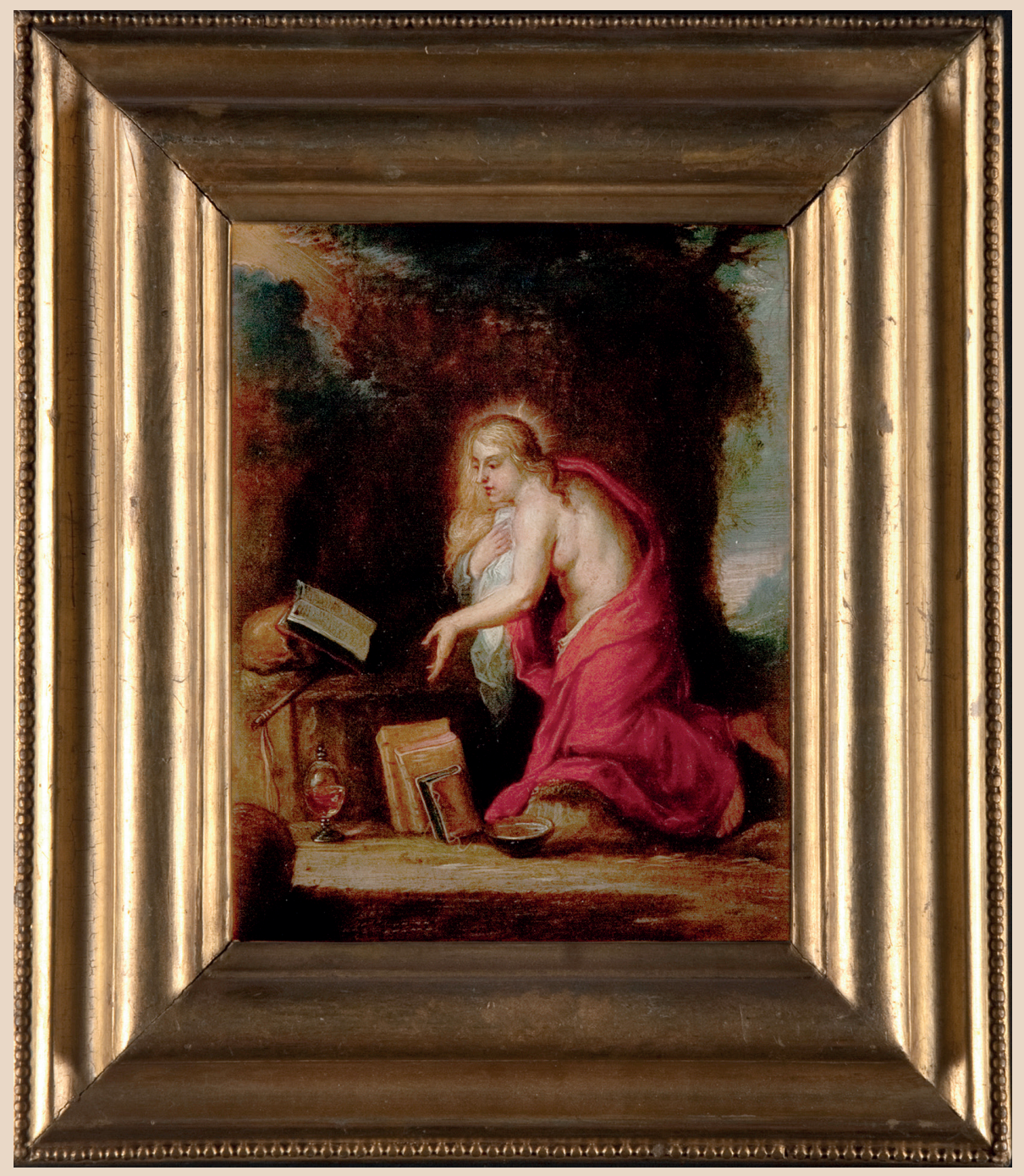

2. "María Magdalena penitente", MOBAT. Foto Viviana Rivas, CNCR-DIBAM. 


\section{"PARÁBOLA DEL BANQUETE DE BODAS"}

(Óleo sobre cobre, 0,63 x 0,78 m; registro 7-241, inventario 1.238: “Castigo del traidor").

En un salón palaciego de notables dimensiones abierto al exterior gracias a una amplia arcada de medio punto ligeramente peraltada desde el que se vislumbra un bucólico paisaje campestre se desarrolla un bullicioso banquete de bodas, en el que se distinguen cuatro grupos de comensales entre otras escenas individualizadas. De la nutrida representación, no en balde se cuentan hasta treinta personajes, en primer plano y escorado a la izquierda aparece un monarca vestido a la moda oriental, tal como algunos personajes, recibiendo consejo a la hora de ordenar atar y encarcelar a un harapiento en un foso semicircular. A su espalda se encuentran los novios y, en el centro, ajenos a la acción, unos invitados en animada conversación, un anciano invitado al festín contempla cómo un joven sirviente le llena su copa de vino, mientras que enfrente otro convidado rebaña un plato ante la mirada distraída de su acompañante. Más apartado todavía se representa a otro grupo de comensales en el que unos dialogan y dos damas se aferran a sendos y lujosos recipientes áureos, tal vez indicando su noble posición. Escenario en el que aparecen algunas naturalezas muertas de evidente calidad tanto en la vajilla de un generoso aparador ladeado como en los jarrones y utensilios que se hallan en primer plano.

El relato está inspirado tanto en los Evangelios canónicos de San Mateo y San Lucas, como en el apócrifo de Santo Tomás, en el que Jesús cuenta la siguiente parábola:

El reino de los cielos es como un rey que preparó un banquete de bodas para su hijo. Mandó a sus siervos que llamaran a los invitados, pero éstos se negaron a asistir al banquete. Luego mandó a otros siervos y les ordenó: "Digan a los invitados que ya he preparado mi comida: ya han matado mis bueyes y mis reses cebadas, y todo está listo. Vengan al banquete de bodas". Pero ellos no hicieron caso y se fueron: uno a su campo, otro a su negocio. Los demás agarraron a los siervos, los maltrataron y los mataron. El rey se enfureció. Mandó su ejército a destruir a los asesinos y a incendiar su ciudad. Luego dijo a sus siervos: "El banquete de bodas está preparado, pero los que invité no merecían venir. Vayan al cruce de los caminos e inviten al banquete a todos los que encuentren". Así que los siervos salieron a los caminos y reunieron a todos los que pudieron encontrar, buenos y malos, y se llenó de invitados el salón 


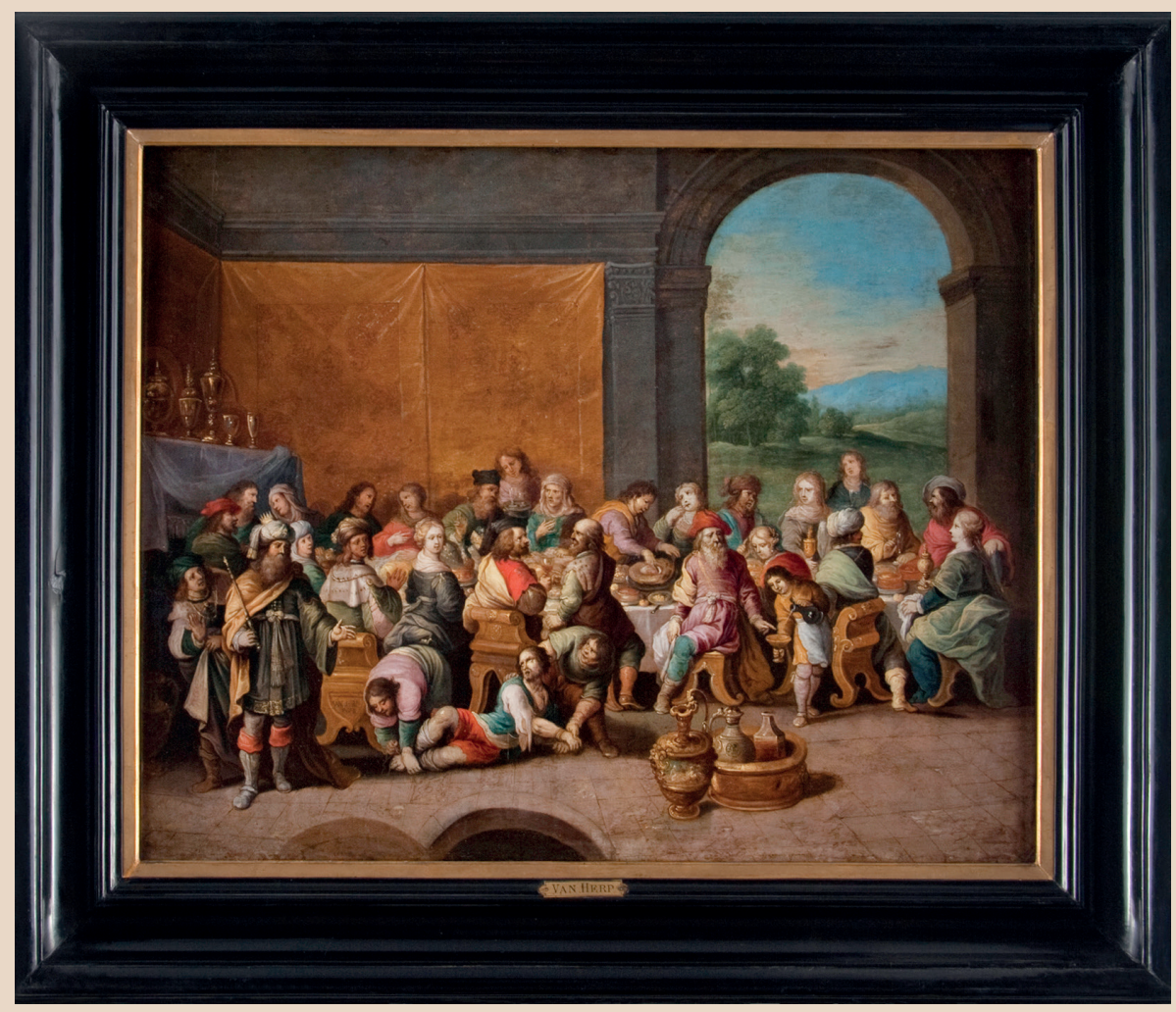

3. "Parábola del banquete de bodas", MOBAT. Foto Viviana Rivas, CNCR-DIBAM.

de bodas. Cuando el rey entró a ver a los invitados, notó que allí había un hombre que no estaba vestido con el traje de boda. "Amigo, ¿cómo entraste aquí sin el traje de boda?”, le dijo. El hombre se quedó callado. Entonces el rey dijo a los sirvientes: "Átenlo de pies y manos, y échenlo afuera, a la oscuridad, donde habrá llanto y rechinar de dientes”. Porque muchos son los invitados, pero pocos los escogidos. 
(Óleo sobre cobre, 0,56 x 72,5 cm; registro 7-5, inventario 1.5: "Azotados por el hambre"; Legado de Eusebio Lillo, 1910).

Reflejadas en una de las planchas de mayores dimensiones se nos aparecen representadas las siete obras corporales, es decir, visitar y cuidar a los enfermos, dar de comer al hambriento, dar de beber al sediento, dar posada al peregrino, vestir al desnudo, visitar y redimir a los cautivos y enterrar a los difuntos; así como una de las espirituales: rogar a Dios por los vivos y los difuntos. Temática que detectamos bien definida en dicha obra. Llama la atención que todos estos preceptos cristianos aparezcan representados mediante una composición abigarrada de personajes en un escenario abierto, muy en la línea argumental de Jordaens, como también sucede con la pintura anterior.

En un paisaje típicamente septentrional de carácter rural y celajes grisáceos se vislumbra, por un lado, un templo y, por otro, una especie de posada formando parte de un caserío fortificado, mientras que en primer plano aparece una multitud de personajes dividida en grupos que ayudan a explicar estas obras caritativas y piadosas. Así pues, de izquierda a derecha, encontramos el sepelio de una mujer desnuda y de su hijito, un grupo de feligreses acudiendo a la iglesia, un anciano de noble aspecto repartiendo vestimentas a los menesterosos semidesnudos, otro grupo de personas a punto de ser hospedadas, otro anciano -quizás sirviente- en primer plano repartiendo pan entre los hambrientos, unos reos siendo liberados al pie de la torre y, por último, otro grupo de personas saciando su sed en el extremo opuesto y siendo atendidas en su enfermedad.

Detectamos algunas similitudes que conectan esta obra con la de idéntica temática, soporte y técnica que custodia el Museo del Louvre de Teniers el Viejo $(0,57 \times 0,77 \mathrm{~m})$, si bien su factura es distinta.

En conclusión, no cabe duda de que tres de estos cobres -como un anónimo quiteño del siglo XVIII y otros dos de un tal A. d'Haemer, quizás pintor belga del siglo XIX, que ahora no relacionamos- los pudo adquirir Eusebio Lillo Robles (Santiago, 1826-1910) en su exilio en Lima, en su posterior estancia en Bolivia, mientras viajó por Europa o tal vez en su propio país; quien, a la postre, los donó al Museo de Bellas Artes de la capital de Chile de donde pasaron al MOBAT. Dichas obras demuestran el refinado gusto artístico del prócer chileno y, ahora felizmente restauradas, vienen a confirmar que por diversos conductos las pinturas flamencas del siglo XVII sobre este tipo de soporte también están presentes en Chile. 


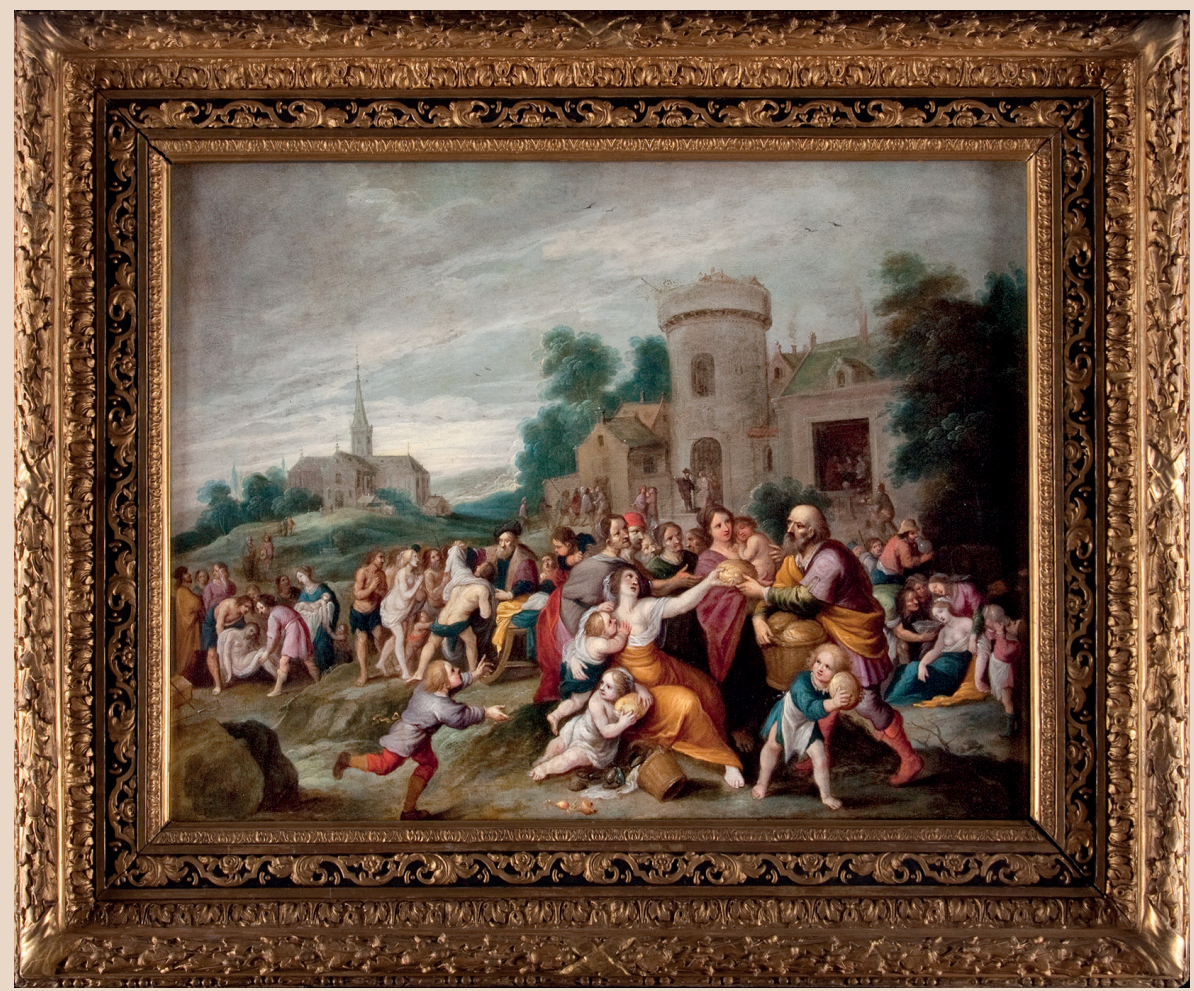

4. "Las Obras de la Misericordia”, MOBAT. Foto Viviana Rivas, CNCR-DIBAM.

\section{REFERENCIAS}

Balis, A. (1985). Mecénat espagnol et art flamand au XVIIe siècle”, en Duvosquel, j. M.; Vandevivere, I., Splendeurs d'Espagne et les villes belges (15001700). Bruselas.

Bargellini, C. (1999). "La pintura sobre lámina de cobre en los virreinatos de la Nueva España y del Perú”. Anales del Instituto de Investigaciones Estéticas, 75, 79-98.

Díaz Padrón, M. (1975). Museo del Prado. Catálogo de pinturas, I: Escuela Flamenca. Siglo XVII, 2 vols. Madrid: Museo del Prado.

Díaz Padrón, M. (1976). Pintura flamenca del siglo XVII en España. Tesis doctoral inédita. Madrid: Universidad Autónoma de Madrid.

Díaz Padrón, M. (1977). “Obras de Guillaume van Herp en España. I”. Archivo Español de Arte, 200, 361-382. 
Díaz Padrón, M. (1978a). “La pintura flamenca en la España de los Austrias”, en Díaz Padrón M. et al., Pedro Pablo Rubens (1577-1640). Exposición Homenaje. Madrid: Ministerio de Cultura.

Díaz Padrón, M. (1978b). “Obras de Guillaume van Herp en España. II”. Archivo Español de Arte, 201, 1-27.

Díaz Padrón, M. (1981). "Precisiones y adiciones a la pintura flamenca del siglo XVII en el Museo de San Carlos de Méjico”. Archivo Español de Arte, 213, 61-76.

Díaz Padrón, M. (1982). “Nuevas pinturas de Guillaume van Herp”. Miscelánea de Arte, 168-173.

Díaz Padrón, M. (1988). "Nuevas pinturas de satélites de Rubens inéditas o mal atribuidas, en colecciones españolas y extranjeras: Van Lint, Van Herp, Th. W. Boschaert y Van Balen”. Archivo Español de Arte, 241, 1-11.

Díaz Padrón, M. (1995). El siglo de Rubens en el Museo del Prado. Catálogo razonado de pintura flamenca del siglo XVII. Barcelona: Prensa Ibérica-Museo del Prado.

Díaz Padrón, M. (1998). "Flandes, España y América Latina en el siglo de Rubens", Rubens y su siglo. México: Landucci.

Díaz Padrón, M. (2003). "Un cobre de Willen van Herp con El sueño del patricio y su esposa del templo de la Virgen de las Nieves". Archivo Español de Arte, 301, 83-88.

Fernández Pardo, F.; Blanco Martínez, J. R. (1996). Pintura flamenca barroca (cobres, siglo XVII). San Sebastián: Diócesis de Calahorra y La CalzadaLogroño.

Ferrer Orts, A. (en prensa). Pintura europea en el Museo O'Higginiano y de Bellas Artes de Talca (Chile).

González Colville, J. (2014). "La historia del Museo O’Higginiano”. Revista de Historia Manso de Velasco, 1, 22-31.

Gruzinski, S. (1994). La guerra de las imágenes. De Cristóbal Colón a "Blade Runner” (1492-2019). 7a reimpresión 2013. México: Fondo de Cultura Económica.

Komanecky, M. et al. (1999). Copper as Canvas. Two centuries of masterpiece paintings on Cooper (1575-1775). Nueva York: Oxford University Press.

Mesa, J.; Gisbert, T. (2005). El Manierismo en los Andes. III Encuentro Internacional sobre Barroco. La Paz: Unión Latina.

Payo Hernanz, R. J. (1998). "Notas para el estudio de la incidencia de la pintura flamenca en la primera mitad del siglo XVII en Burgos. La huella de Rubens y Van Dyck”. BIFG, año LXXVII, 217, 289-320.

Rodríguez Domingo, J. M. (2005). "La serie de cobres flamencos del Obispado de Guadix". Cuadernos de Arte, 36, 99-117.

Sánchez Rivera, J. A. (2011). "Sobre una serie de cobres flamencos de pintores en la estela de Rubens". Anales de Historia del Arte, Volumen Extraordinario, 483-505. 
Sanzsalazar, J. (2001). "Un dibujo de Willem van Herp de la serie de los Moncada, en la Galería Nacional de Edimburgo”. Boletín del Seminario de Estudios y Arqueología, 67, 283-289.

Sanzsalazar, J. (2003). "Un banquete familiar de Willem van Herp en Bad Harzburg”. Goya, 297, 356-359.

Sanzsalazar, J. (2013). "Fuentes de inspiración, iconografía y retrato de Willem van Herp en dos cobres del coleccionismo español”. Boletín del Seminario de Estudios de Arte, 79, 43-50.

Valdivieso, E. (1973). “Obras inéditas de Willem van Herp”. Boletín del Seminario de Estudios de Arte y Arqueología, XXXIX, 483-488. 